DPST-87-596

\title{
ABSORPTION OF CARBON DIOXIDE IN WASTE TANKS (U)
}

by

\author{
D. T. Hobbs
}

Westinghouse Savannah River Company

Savannah River Site

Aiken, South Carolina 29808

This is a Technical Report

This report was prepared in connection with work done under Contract No. DE-AC09-89SR18035 with the U.S. Department of Energy. By acceptance of this report, the publisher and/or recipient acknowledges the U.S. Government's right to retain a nonexclusive, royalty-free license in and to any copyright covering this report, along with the right to reproduce and to authorize others to reproduce all or part of the copyrighted report. 
TECHNICAL DIVISION

SAVANNAH RIVER LABORATORY

MEMORANDUM

\author{
Bicarbonate, Carbonate, \\ Hydroxide Depletion, Model, \\ Radioactive Wastes \\ DPST-87-596
cC: G. T. Wright, 703-H
C. G. Goodlet, 703-S
J. E. Black, 703-H
P. D. d'Entremont, 703-H
D. L. McIntosh, 773-A
R. M. Wallace, 773-A
H. D. Harmon, 773-A
R. S. Ondrejcin, 773-A
D. F. Bickford, 773-A
J. W. Congdon, 773-A
R. E. Eibling, 773-A
L. E. Landon, 704-T
S. B. Oblath, 773-A
D. D. Walker, 773-A
P. E. Zapp, 773-A

SRL Records (4), 773-A

September 3, 1987

TO: J. R. WILEY, 773-A

FROM: D. T. HOBBS, 773-A DT

\section{ABSORPTION OF CARBON DIOXIDE IN WASTE TANKS}

\section{SUMMARY}

Air flow rates and carbon dioxide concentrations of air entering and exiting eight $\mathrm{H}$-Area waste tanks were monitored for a period of one year. The average instantaneous concentration of carbon dioxide in air is within the range reported offsite, and therefore is not affected by operation of the coal-fired power plant adjacent to the tank farm. Waste solutions in each of the tanks were observed to be continuously absorbing carbon dioxide.

The rate of absorption of carbon dioxide decreased linearly with the $\mathrm{pH}$ of the solution. Personnel exposure associated with routine sampling and analysis of radioactive wastes stored at/SRP to determine the levels of corrosion inhibitors in solution couta be reduced by monitoring the absorption of carbon dioxide and using the relationship between $\mathrm{pH}$ and carbon dioxide absorption to determine the free hydroxide concentration in solution.

Based on the average instantaneous concentration of carbon dioxide in air and the fraction of carbon dioxide absorbed in Tank $42 \mathrm{H}$, the rate of change in the $\mathrm{pH}$ and the total carbonate concentration of 
the washed sludge supernate has been calculated. Good agreement between experimental and calculated data was found, verifying the previously reported model for calculating the rate of hydroxide depletion in salt solutions.

\section{INTRODUCTION}

Full-scale demonstrations of the aluminum dissolution and washing of sludge and the decontamination of salt solution were conducted in 1983. Since the demonstrations, the washed sludge and washed precipitate have been stored in Tanks $42 \mathrm{H}$ and $48 \mathrm{H}$, respectively. After storage for approximately twenty months, the free hydroxide level in both tanks had fallen below the minimum level of $0.01 \mathrm{M}$ established by the current technical standard.1 At that time, additional sodium hydroxide was added to the storage tank to raise the level to within the technical standard. 2

Because of the increased potential for tank corrosion and the possibility of significantly higher sodium levels in the melter feed as the result of adding sodium hydroxide 3 , a program was initiated to determine the mechanism and rate of hydroxide depletion and to develop a model for calculating the time dependent concentrations of inhibitors in solution. 4

\section{EXPERIMENTAL}

Carbon dioxide levels were determined using a Foxboro Miran ${ }^{\mathrm{TM}} 101$ portable gas analyzer. The analyzer was zeroed with purified nitrogen and calibrated with two different standard carbon dioxide/air gas mixtures prior to each weekly measurement. The instantaneous atmospheric carbon dioxide level was measured at each tank. The analyzer was then placed in contact with the air being exhausted from the vent stack via plastic tubing. After 1-2 minutes a constant, instantaneous carbon dioxide reading was recorded. Flow rates were recorded using the flowmeter gauges located at each tank. The flow rate of Tank $42 \mathrm{H}$ was determined using a fan-type anemometer.

Dip samples from Tank $42 \mathrm{H}$ were taken by Waste Management operations and transported to SRL. Upon arrival at SRL, the samples were placed into the high level cells. Each sample was well mixed prior to opening the sample bottle. After opening, the mixture was filtered through a Nalgene ${ }^{\mathrm{M}} 0.45 \mu \mathrm{m}$ disposable filter. The solids were discarded. The filtrate was then analyzed to determine inhibitor levels. During processing of the dip samples, exposure of the liquid to air was minimized to limit the absorption of carbon dioxide. Similar procedures were used by the F-Area Laboratory to determine inhibitor levels in waste solutions stored in the other H-Area Tanks.

Weather data were obtained from the SRL Weather Center. Statistical analyses of the experimental data were performed on a MacIntosh ${ }^{\mathrm{TM}}$ Plus personal computer using the Statview $512+^{\mathrm{TM}}$ software package. 

Concentrations were measured during daylight and after sunset in a variety of weather and seasonal conditions. No statistically significant variations in carbon dioxide concentrations were observed with respect to time, temperature, wind direction, wind speed, and season (see Tables I and II). Higher average concentrations (ca. $15 \mathrm{ppm}$ ) were observed for the fall and winter seasons as compared to spring and summer. This variation is within the normal seasonal variations for atmospheric carbon dioxide concentrations.

It was believed that operation of the coal-fired power plant adjacent to the waste tanks could significantly alter the atmospheric carbon dioxide concentrations. 8 However, this was not observed. The average concentration downwind of the power plant was $361 \pm 16 \mathrm{ppm}$ as compared to $360 \pm 20$ ppm upwind.

\section{Carbon Dioxide Absorption}

The average air flow rate, atmospheric carbon dioxide concentration, and absorption fraction for each tank is presented in Table III. The absorption fraction is calculated by dividing the difference of the carbon dioxide concentrations entering and exiting the tank by the carbon dioxide concentration entering the tank (equation 3).

$$
\text { Absorption Fraction }=\left\{\left[\mathrm{CO}_{2}\right]_{\text {enter }}-\left[\mathrm{CO}_{2}\right]_{\text {exit }}\right\} /\left[\mathrm{CO}_{2}\right]_{\text {enter }}
$$

Tanks $38 \mathrm{H}, 39 \mathrm{H}, 41 \mathrm{H}, 43 \mathrm{H}, 49 \mathrm{H}$, and $50 \mathrm{H}$ showed no significant changes in the measured absorption of carbon dioxide during the monitoring period. Approximately 778 of the carbon dioxide entering these tanks was absorbed.

In contrast, the absorption fraction in Tanks $42 \mathrm{H}$ and $48 \mathrm{H}$ was observed to change significantly. Tank $42 \mathrm{H}$ showed a very low absorption fraction during the first four months followed by an abrupt increase. The absorption fraction remained at the higher value during the remaining eight months. Tank $48 \mathrm{H}$ showed a high absorption fraction during the first eight months of monitoring. The absorption fraction decreased steadily during the final four months.

The changes in the rate of carbon dioxide absorption in these two tanks are due to changes in the concentration of free hydroxide in the liquid phase. From January through April, the free hydroxide level in the Tank $42 \mathrm{H}$ supernate was approximately $1.0 \times 10^{-4}$ molar $(\mathrm{pH} 10)$. At this low free hydroxide level, the thermodynamics are less favorable for carbon dioxide absorption, and, thus, the absorption is low. In early May, additional sodium hydroxide was added to Tank $42 \mathrm{H}$ to raise the free hydroxide level to 0.0327 molar ( $\mathrm{pH} 12.5)$. At the increased free hydroxide level, the carbon dioxide absorption is more favorable and the observed absorption fraction was increased by a factor of about six (see Table III). 
In the case of Tank $48 \mathrm{H}$, the decrease in the absorption fraction was accompanied by a decrease in the free hydroxide concentration from $0.12 \mathrm{M}$ to $0.064 \mathrm{M}$. The lower free hydroxide level resulted in lower absorption rates in the waste tank.

Linear regression analysis of the data was carried out to determine if there existed any correlations between any of the measured variables and the absorption fraction. Table IV shows a list of selected coefficients of correlation. Based on the low coefficients, the rate of absorption or absorption fraction did not correlate with time-of-day, date, atmospheric carbon dioxide concentration, wind direction, wind speed, or temperature. Higher coefficients were observed for nitrate concentration, specific gravity, and $\mathrm{pH}$.

From reaction kinetics and thermodynamics, one would expect the air flow rate and the carbon dioxide concentration to significantly affect the absorption. However, in the case of these data, the range of both of these variables is limited and statistical correlation may not be observed.

The highest coefficient observed was between the $\mathrm{pH}$ of the solution and the absorption fraction for each tank. The pH was calculated from analytically determined hydroxide ion concentrations using equation 4.

$$
\mathrm{pH}=14+\log \left[\mathrm{OH}^{-}\right]
$$

Figure 1 shows a plot of the average $\mathrm{ph}$ of the solution in each tank versus the average absorption fraction measured for each of the waste tanks. The solid line represents the linear least squares fit of the data and had the form;

$$
y=0.165 x-1.569 \text {, }
$$

where $\mathrm{x}=\mathrm{pH}$ and $\mathrm{y}=$ absorption fraction. The correlation coefficient for the linear regression analysis was 0.948 . The dash lines represent the 958 confidence bands about the mean of the absorption fraction.

\section{Determination of Hydroxide Levels by Carbon Dioxide Monitoring}

The linear correlation between the $\mathrm{pH}$ of the solution and the absorption fraction may have practical application in monitoring inhibitor levels in the waste tanks. Currently, the hydroxide concentration in waste solutions is determined by sampling the contents of the waste tank and determining the concentration by titration. Alternatively, one could measure the fraction of carbon dioxide absorbed and use equation 6 to calculate the hydroxide concentration. Equation 6 is obtained by substituting equation 4 into equation 5 for the $\mathrm{pH}$ and rearranging to give an expression for the molar hydroxide concentration in terms of the absorption fraction.

$$
\left[\mathrm{OH}^{-}\right]=10^{[\text {(Absorption Fraction }-0.741) / 0.165]}
$$


supernate were calculated as a function of time using the carbon dioxide absorption model.

Figures 3 and 4 show the calculated $\mathrm{pH}$ and Figures 5 and 6 show the calculated carbonate concentrations, respectively, for the time periods, December, 1985 to May, 1985 and May, 1985 to March, 1986. Experimentally determined $\mathrm{pH}$ and carbonate levels of supernate samples taken from Tank $42 \mathrm{H}$ during these times are also plotted.

Two calculated curves are plotted for each case. These represent the minimum and maximum rates at which the $\mathrm{pH}$ and carbonate levels are reached and are based on the standard deviation of the experimentally measured carbon dioxide level, air flow rate, and absorption fraction.

There was good agreement between the observed and calculated pH and carbonate values for both of these time periods verifying that the carbon dioxide absorption model can be used to calculate the time dependent concentrations of hydroxide and carbonate in waste solutions stored in SRP waste tanks. The differences between the experimental and calculated values can be attributed to experimental errors in sampling and analytical techniques and assuming constant flow rates and absorption fractions during these times periods.

The $\mathrm{pH}$ decreased in a normal titration-like curve for a strong base for both the observed and calculated cases. The lower limit at $\mathrm{pH}$ 9.5 - 10.0 is consistent with formation of a bicarbonate/carbonate buffer system. The steady-state concentration of total carbonate is dependent on the initial hydroxide concentration and the partial pressure of the carbon dioxide in the air.

The total carbonate concentration increased linearly as expected by the mass-transfer limited absorption of carbon dioxide. During the range of $\mathrm{pH}$ values spanned, the predominant carbonate species changes from carbonate (high $\mathrm{pH}$ ) to bicarbonate (low $\mathrm{pH}$ ).

\section{OUALITY ASSURANCE}

The experimental results referenced in this memorandum were obtained in accordance with the Savannah River Laboratory Quality Assurance Program and Defense Waste Section Quality Assurance Plan. 9 Experimental procedures and data are recorded in laboratory notebooks DPSTN \#4379 and $\$ 4461$ maintained by D. T. Hobbs. 
If the absorption fraction indicated that the hydroxide concentration was close to the lower limit of the technical standard, a supernate sample would then be taken to confirm the hydroxide concentration. Personnel exposure would be significantly reduced by decreasing the number of liquid samples.

In addition to lower personnel exposure, the carbon dioxide monitoring instrument is portable and the technique is rapid. The ambient air analyzer used in this study weighed approximately eighteen pounds including the rechargeable battery pack and was easily operated by a single individual. Calibration of the instrument and sampling of the eight waste tanks routinely took less than one hour to complete.

\section{Abserption Model}

Because of the increased potential for corrosion of the carbon steel waste tank as free hydroxide is depleted, a model of the waste tanks was developed that would allow one to calculate the time dependent concentrations of hydroxide and carbonate species. A schematic representation of the model is shown in Figure 2 .

The contents of each waste tank are assumed to be comprised of three phases, a gas phase, a liquid phase, and a solid phase. The gas phase is predominantly air with other volatile compounds that may be present (eg. benzene in washed precipitate slurry). The liquid phase consists of the sodium salts of inorganic and organic anions. The solid phase is comprised of inert water insoluble species which do not affect thermodynamic equilibria in either of the other two phases.

Air is swept over and contacts the liquid in the waste tank. Carbon dioxide in the air is absorbed by the liquid phase and reacts instaneously with hydroxide to form bicarbonate (equation 1). If sufficient hydroxide is present, the bicarbonate reacts with additional hydroxide to form carbonate (equation 2). Carbon dioxide is continually absorbed until the partial pressure of carbon dioxide in equilibrium with the liquid phase equals the partial pressure of carbon dioxide in the air entering the tank.

The kinetics of reactions between hydroxide and carbon dioxide or bicarbonate are extremely fast. Thus, the rate determining step in depleting hydroxide in the liquid phase is the transfer of carbon dioxide across the gas-liquid interface. 4 The rate of carbon dioxide absorbed is calculated by multiplying the air flow rate through the tank by the concentration of carbon dioxide in air and by the fraction of carbon dioxide absorbed (equation 7).

$$
\text { Rate }=\text { Elow Rate } \times\left[\mathrm{CO}_{2}\right] \text { air } \times \text { Absorption Fraction }
$$

Assuming a constant air flowrate through Tank $42 \mathrm{H}$ at 430 ( \pm 108 ) scfm, using the average atmospheric carbon dioxide concentration $(361 \pm 19 \mathrm{ppm})$, and assuming that an absorption fraction of $0.581 \pm$ 0.039 , the $\mathrm{pH}$ and the total carbonate concentrations in Tank $42 \mathrm{H}$ 


\section{REEERENCES}

1. WMI-84-11-14, "Tank 42 Supernate Outside Technical Standards", November 7,1984 .

2. DPSTS-241-5.01, "Limitations on waste Tank Contents".

3. D. T. Hobbs, DPST-85-861, "Hydroxide Depletion in Dilute Supernates Stored in Waste Tanks", October 10, 1985.

4. D. T. Hobbs and R. M. Wallace, DPST-85-846, "Hydroxide Depletion in Waste Storage Tanks by Reaction with Carbon Dioxide", October 14, 1986.

5. D. T. Hobbs, September Monthly Status Report-Interim Waste Technology Division, October 7, 1985.

6. P. D. D'Entremont, Technical Authorization No. 2-1099, "Monitoring Hydroxide Depletion of Dilute Supernate in Tank 42 ".

7. J. M. Wallace and P. U. Hobbs, "Atmospheric Science: An Introductory Survey", Academic Press, New York, 1977, p. 10.

8. D. T. Hobbs, DPST-86-735, "Absorption of Carbon Dioxide in Waste Tanks", October 21, 1986.

9. Savannah River Laboratory Quality Assurance Manual, DPSTQA-83-4-2, November 1983. 


\section{Table I}

ATMOSPHERIC CARBON DIOXIDE CONCENTRATIONS

Season

Spring (March-May)

Summer (June-August)

Fall (September-November)

Winter (December-February)

All Seasons
Average concentration

(ppm)

$347 \pm 7$

$352 \pm 17$

$363 \pm 18$

$370 \pm 19$

$361 \pm 19$ 
TABLE II

\section{IINEAR REGRESSION ANALYSIS OF ATMOSPHERIC} CARBON DIOXIDE CONCENTRATION

$x$

Date

Time

Wind Direction

Wind speed

Temperature $\mathbf{x}$

$\mathrm{CO}_{2}$ Concentration

$\mathrm{CO}_{2}$ Concentration

$\mathrm{CO}_{2}$ Concentration

$\mathrm{CO}_{2}$ Concentration

$\mathrm{CO}_{2}$ Concentration
CORREIATION

COSEEICIENT

0.339

0.123

0.230

0.099

0.496 
TABLE III

AVERAGE AIR FLOW RATES AND CARBON DIOXIDE ABSORPTION FRACTIONS FOR H-AREA WASTE TANKS

\begin{tabular}{|c|c|c|c|c|}
\hline TANK & COMPOSITION & $\begin{array}{l}\text { ELOWRATE } \\
\text { (sCfm) }\end{array}$ & $\begin{array}{l}\text { [CO2] } \\
\text { ENTER } \\
\text { (ppm) }\end{array}$ & $\begin{array}{l}\text { ABSORPTION } \\
\text { ERACTION }\end{array}$ \\
\hline 50 & $\begin{array}{l}\text { Decontaminated } \\
\text { Supernate }\end{array}$ & $293 \pm 35$ & $362 \pm 18$ & $0.746 \pm 0.037$ \\
\hline 49 & $\begin{array}{l}\text { Spent Wash } \\
\text { Water }\end{array}$ & $336 \pm 11$ & $357 \pm 14$ & $0.697 \pm 0.050$ \\
\hline 48 & $\begin{array}{l}\text { Washed Precipit } \\
\text { - High }[\mathrm{OH}] \\
\text { - Low }[\mathrm{OH}]\end{array}$ & $\begin{array}{l}266 \pm 44 \\
231 \pm 26\end{array}$ & $\begin{array}{l}350 \pm 14 \\
361 \pm 15\end{array}$ & $\begin{array}{l}0.715 \pm 0.046 \\
0.400 \pm 0.055\end{array}$ \\
\hline 43 & LHW & $311 \pm 60$ & $361 \pm 19$ & $0.834 \pm 0.056$ \\
\hline 42 & $\begin{array}{c}\text { Washed Sludge } \\
\text { - Low [OH] } \\
\text { - High }[\mathrm{OH}]\end{array}$ & $\begin{array}{l}430 \\
430\end{array}$ & $\begin{array}{l}355 \pm 22 \\
364 \pm 21\end{array}$ & $\begin{array}{l}0.096 \pm 0.023 \\
0.581 \pm 0.039\end{array}$ \\
\hline 41 & Evaporator Conc. & $351 \pm 21$ & $366 \pm 22$ & $0.756 \pm 0.065$ \\
\hline 39 & HHW & $264 \pm 62$ & $360 \pm 20$ & $0.791 \pm 0.069$ \\
\hline 38 & LHW & $268 \pm 40$ & $359 \pm 18$ & $0.798 \pm 0.052$ \\
\hline All & - & $290 \pm 54$ & $361 \pm 19$ & $0.695 \pm 0.152$ \\
\hline A11 ex & $=42$ and 48 & $299 \pm 53$ & $361 \pm 19$ & $0.770 \pm 0.070$ \\
\hline
\end{tabular}


TABLE IV

\section{LINEAR REGRESSION ANALYSIS OF ABSORPTION FRACTION}

\begin{tabular}{llc}
\multicolumn{1}{c}{$\mathbf{x}$} & $\mathbf{x}$ & $\frac{\text { CORREIATION }}{\text { COEFICIENT }}$ \\
Date & Absorption Fraction & 0.037 \\
Time & Absorption Fraction & -0.094 \\
Flow Rate & Absorption Fraction & 0.273 \\
$\mathrm{CO}_{2}$ Conc. & Absorption Fraction & -0.087 \\
Wind Direction & Absorption Fraction & -0.036 \\
Wind Speed & Absorption Fraction & $4.8 \times 10^{-4}$ \\
Temperature & Absorption Fraction & 0.023 \\
Nitrate & Absorption Fraction & 0.641 \\
Concentation & Absorption Fraction & 0.554 \\
Specific Gravity & Absorption Fraction & 0.948 \\
pH &
\end{tabular}




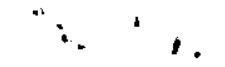

J. R. Wiley

FIGURE 1. Plot of Average Absorption Eraction Versus Average Calculated $\mathrm{pH}$

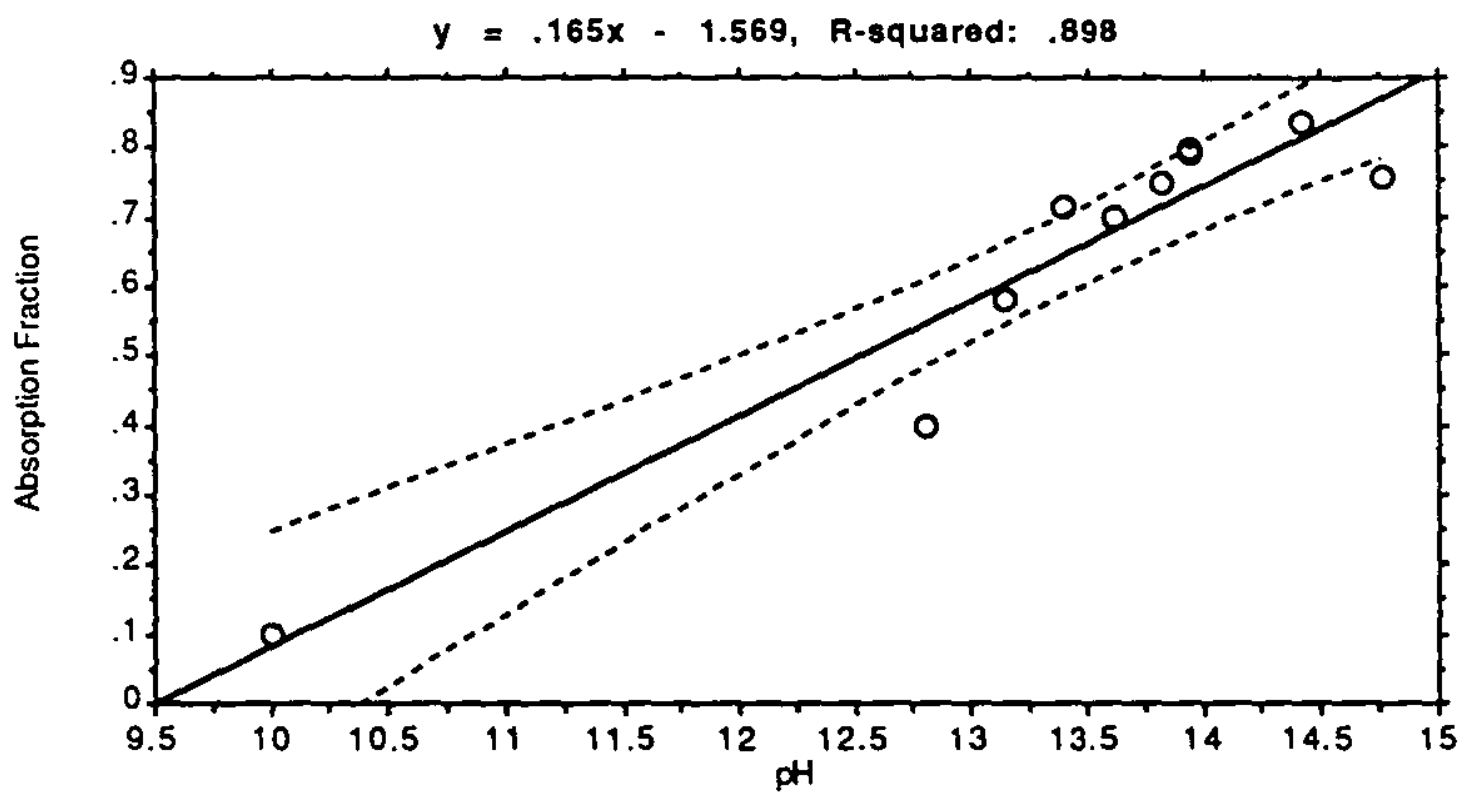


FIGURE 2. Schematic Representation of Waste Tank Absorption Model

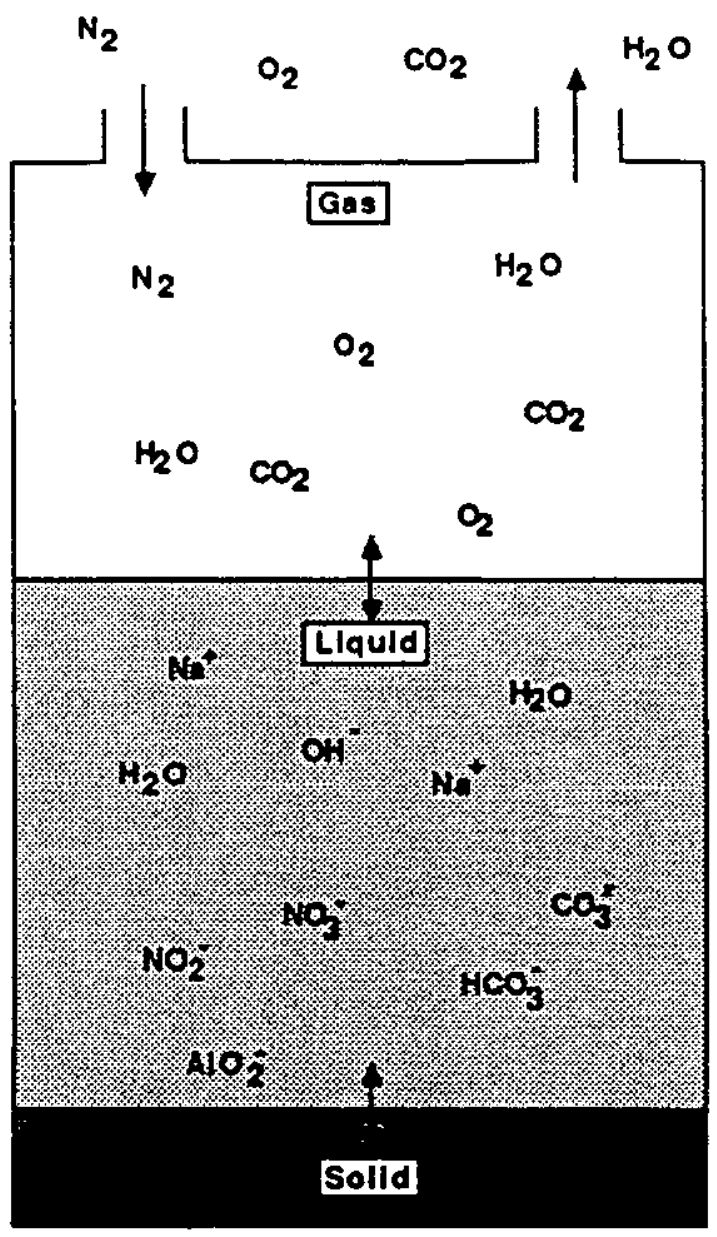

Steady-State : $p\left(\mathrm{CO}_{2}\right)^{\text {alr }}=p\left(\mathrm{CO}_{2}\right)^{\operatorname{tank}}$ 
.

J. R. Wiley

$-15-$

こミンーミーーミミ

FIGURE 3. Calculated and Observed $\mathrm{pH}$ of Washed Sludge

Supernate from December, 1984 to May, 1985.

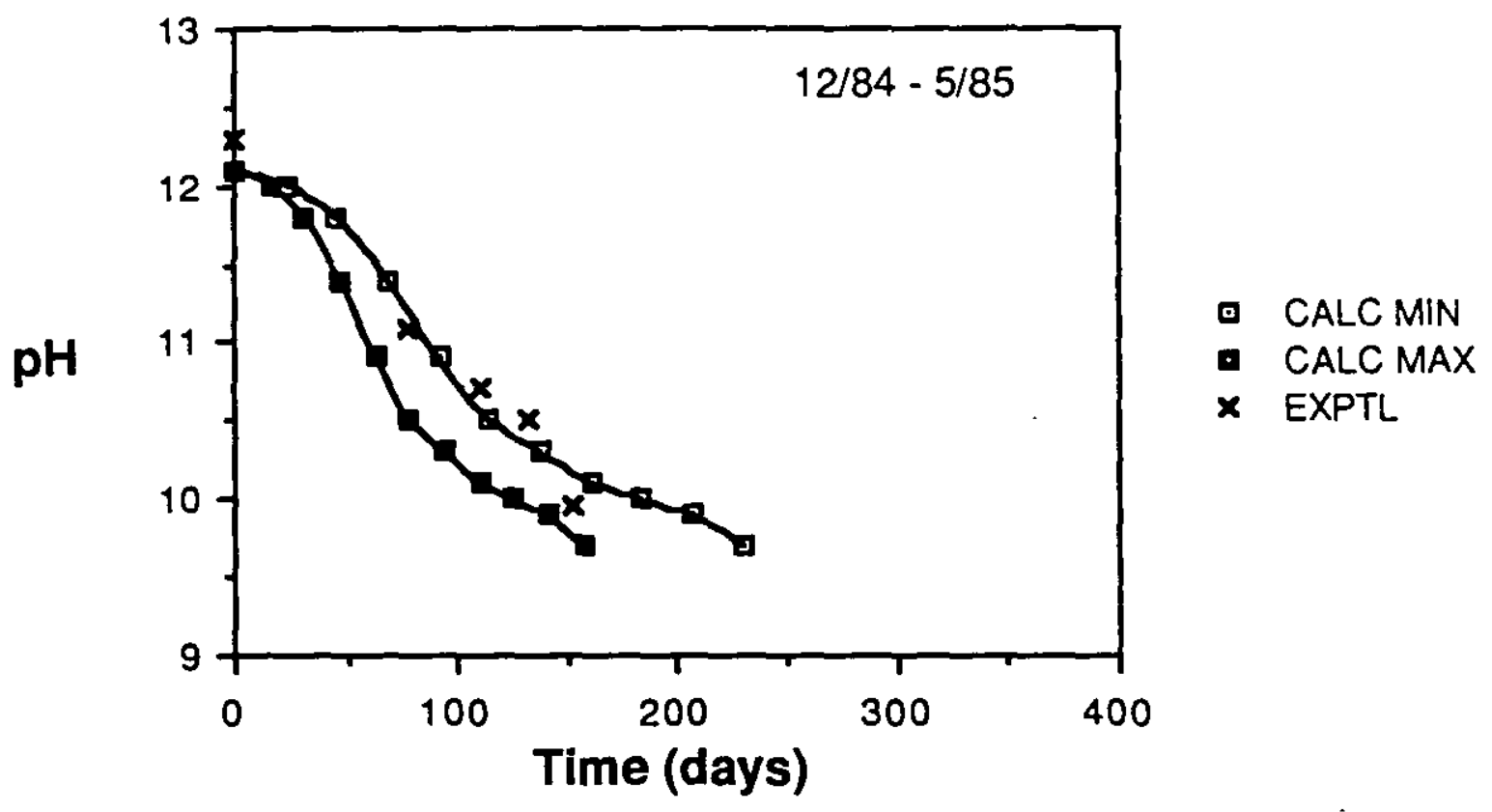


FIGURE 4. Calculated and Observed pH of Washed Sludge Supernate from May, 1985 to March, 1986.

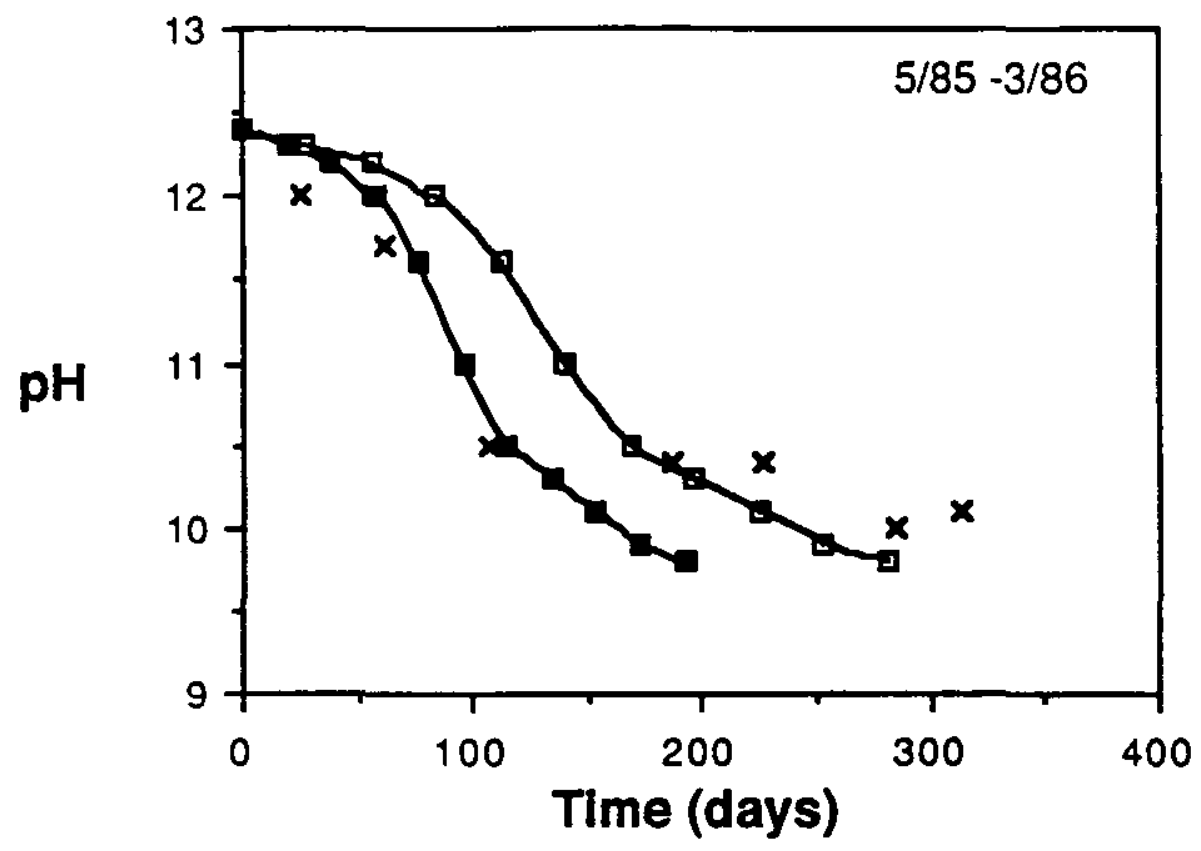

a CALC MIN

- CALC MAX

* EXPTL 
FIGURE 5. Calculated and Observed Total Carbonate in Hashed Sludge Supernate from December, 1984 to May, 1985.

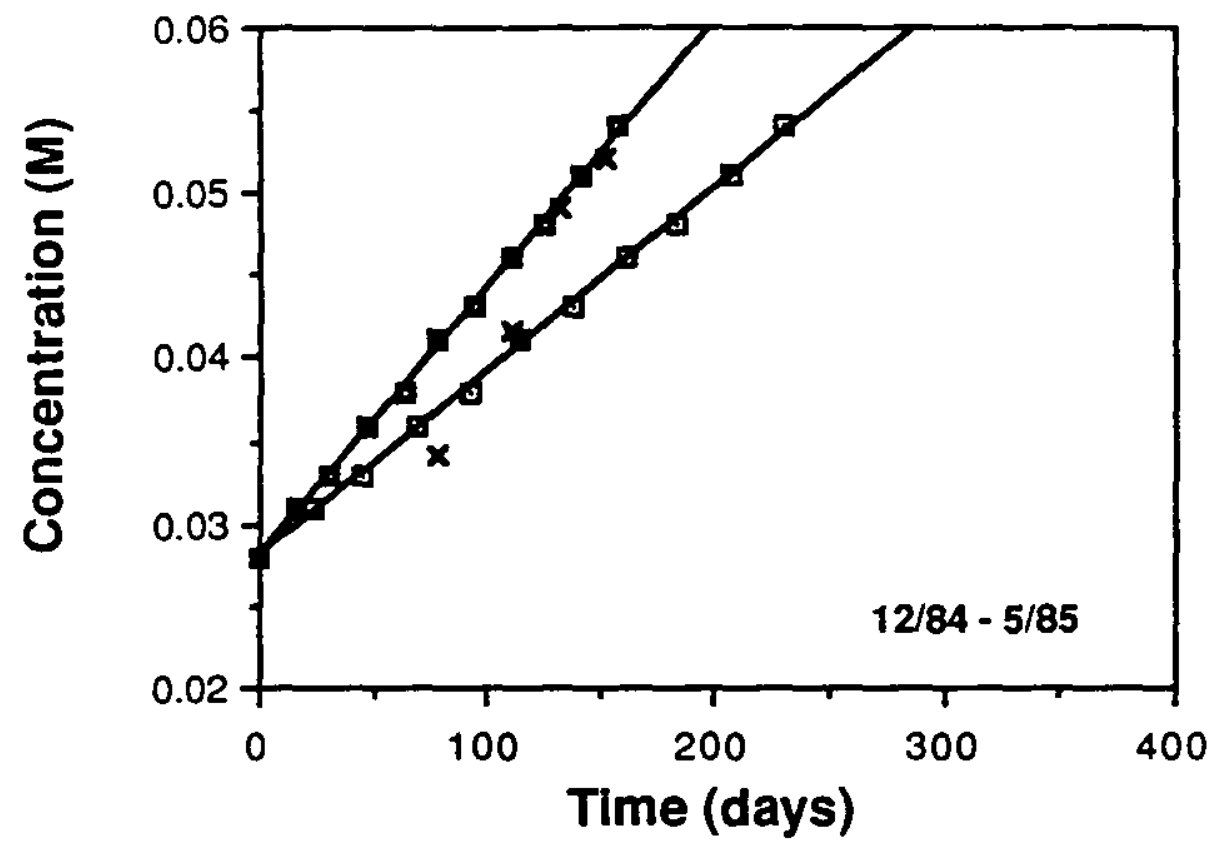

- CALC MIN

- CALC MAX

× EXPTL 
EIGURE 6. Calculated and Observed Total Carbonate in

Washed Sludge Supernate from May, 1985 to

March, 1986.

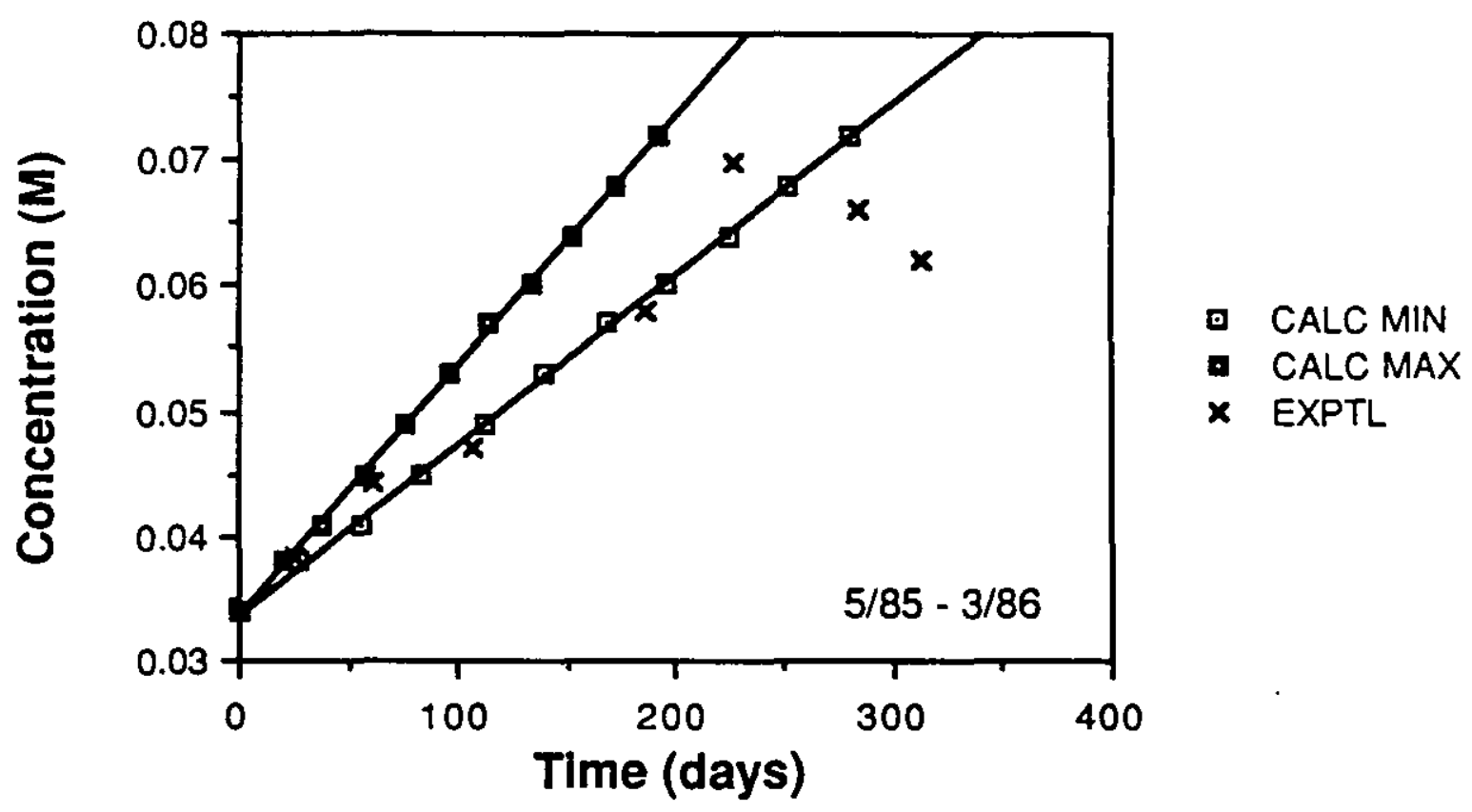

